\title{
Transition Metal Ions as Efficient Catalysts for Facile Ortho-Formylation of Phenols under Vilsmeier-Haack Conditions
}

\author{
F. Aneesa, ${ }^{1}$ K. C. Rajanna, ${ }^{2}$ Y. Arun Kumar, ${ }^{1}$ and M. Arifuddin ${ }^{3}$ \\ ${ }^{1}$ Department of Chemistry, Muffakham Jah College of Engineering and Technology, Mount Pleasant, Banjara Hills, \\ Hyderabad 500034, India \\ ${ }^{2}$ Department of Chemistry, Osmania University, Hyderabad 500007, India \\ ${ }^{3}$ National Institute of Pharmaceutical Education and Research (NIPER) Balanagar, Hyderabad 500037, India \\ Correspondence should be addressed to K. C. Rajanna, kcrajannaou@yahoo.com
}

Received 31 August 2012; Revised 16 October 2012; Accepted 20 October 2012

Academic Editor: Paul Watts

Copyright () 2012 F. Aneesa et al. This is an open access article distributed under the Creative Commons Attribution License, which permits unrestricted use, distribution, and reproduction in any medium, provided the original work is properly cited.

Aromatic compounds (phenols), when treated with Vilsmeier Haack (V-H) reagent in the presence of transition metal ions such as $\mathrm{Cu}(\mathrm{II}), \mathrm{Ni}(\mathrm{II}), \mathrm{Co}(\mathrm{II}), \mathrm{Cd}(\mathrm{II})$, and $\mathrm{Zn}$ (II) under reflux conditions, afforded corresponding ortho-formyl derivatives in good yields. Under normal conditions the metal-ion-free $\mathrm{V}-\mathrm{H}$ reactions are too sluggish and resulted in poor yields. This protocol provides highly regioselective formylation under a mild and efficient condition with simple workup.

\section{Introduction}

One of the most fascinating developments seen in organic synthesis during the recent years is the application of transition metals for ortho functionalization of aromatic compound [1]. Ever since the application of transition metals in organic reactions is introduced, a number of chemical reactions have been reported to functionalize nonreactive aromatic $\mathrm{C}-\mathrm{H}$ bond ortho to hydroxyl and other functional groups [2]. Formylation of aromatic compounds is a classical reaction in inorganic chemistry and numerous methods are available [3]. The formyl substituted phenols are important compounds in organic chemistry [4], for instance substituted salicyladehydes (O-hydroxybenzaldehydes) are important intermediates in organic synthesis for the preparation of a variety of oxygen containing heterocyclic compounds and as a source for silane ligands [5], and only few of them are commercially available even today. Even though the synthesis of salicyladehydes from corresponding phenols has been carried out by various methods, most of them afforded only low yields, leading to deformylation or lack in regioselectivity [6]. The Vilsmeier-Haack reaction is a mild method for the introduction of a formyl group to various aromatic and heteroaromatic compounds $[7,8]$. It is also utilized in the synthesis of a large number of heterocyclic compounds [911]. Some interesting cyclization reactions under Vilsmeier conditions have been reported recently [12-18]. It is seen that despite of good formylating ability of $\mathrm{V}-\mathrm{H}$ reagent only sporadic reports are found on ortho-formylation of phenols using V-H reaction. One patent is reported in 1927 for synthesis of vanillin by formylation of Guaiacol with nmethyl formanilide-phosphoryl chloride complex $[19,20]$. It is very well known that $\mathrm{V}-\mathrm{H}$ reagent will produce aryl formats from phenols. In continuation of our ongoing work on $\mathrm{V}-\mathrm{H}$ reactions under various modified conditions we have reported a certain $\mathrm{V}-\mathrm{H}$ reaction in micellar media [21] and under ultrasonic conditions [22].

\section{Results and Discussion}

Recently we have found that metal ions are good promoters for a variety of organic reactions such as Hunsdiecker reaction [23] and bromination reaction [24-27]. Herewith now we report the selective formylation of phenols promoted by metal ions under V-H conditions. Nevertheless, in one of the earlier reports metal ions in conjunction with $\mathrm{DMF} / \mathrm{POCl}_{3}$ have been used for one step deprotective O-formylation of 

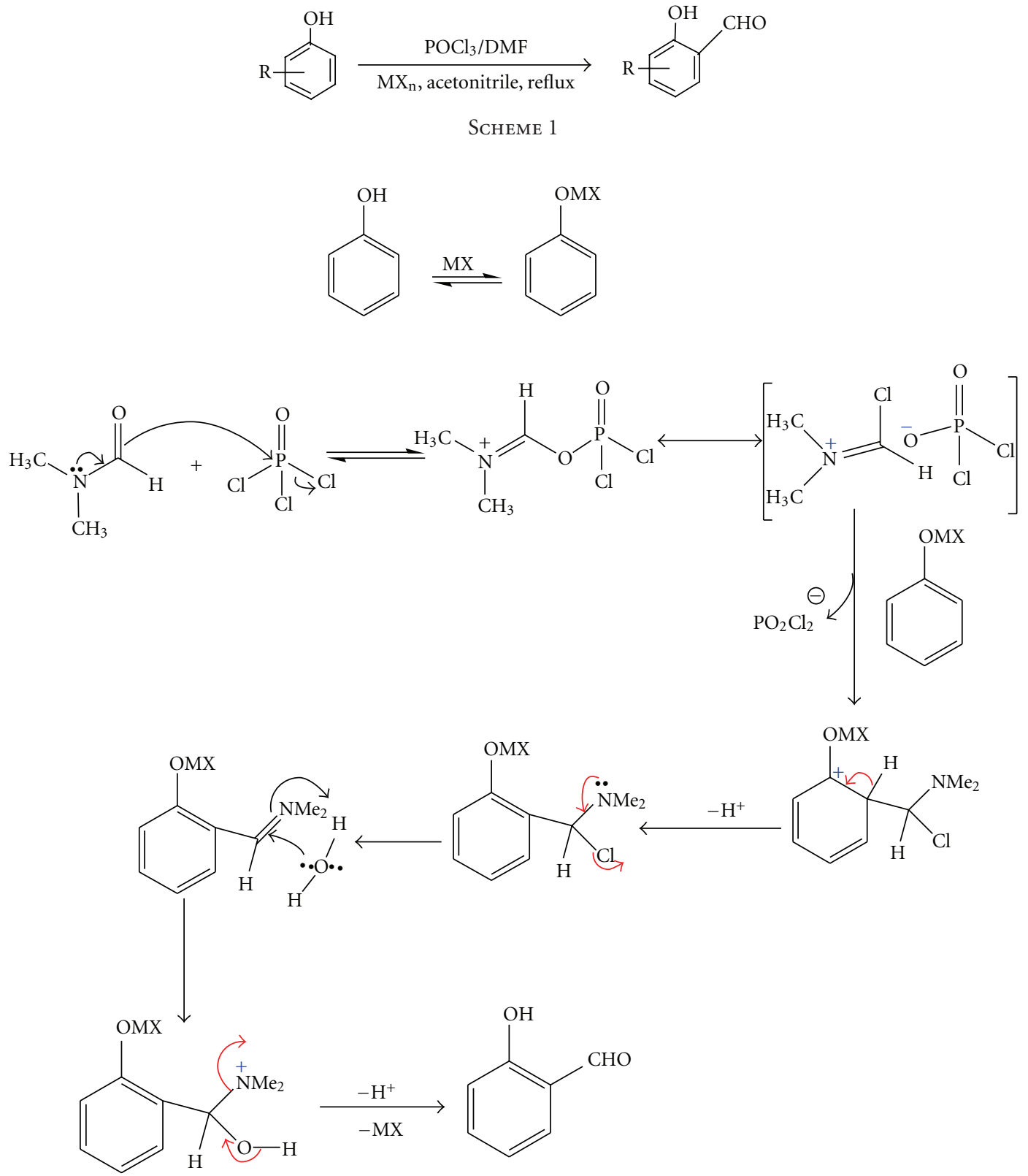

$$
\begin{aligned}
& \ominus \\
& \mathrm{H}^{+}+\left[\mathrm{PO}_{2} \mathrm{Cl}_{2}\right] \stackrel{\mathrm{HPO}_{2} \mathrm{Cl}_{2}}{\text { SCHEME 2 }}
\end{aligned}
$$

bis-O-tertiary butyl diphenyl silyl (O-TBDPS) aromatic diol [28].

Aromatic compounds (phenols) when treated with V-H reagent in the presence of metal salts such as $\mathrm{Cu}(\mathrm{II}), \mathrm{Ni}(\mathrm{II})$, $\mathrm{Co}(\mathrm{II}), \mathrm{Cd}(\mathrm{II})$, and $\mathrm{Zn}$ (II) in their nitrates form under reflux conditions afforded corresponding ortho-formyl derivatives (Scheme 1) in good yields (Table 1). All products were characterized by the physical data IR and ${ }^{1} \mathrm{H}-\mathrm{NMR}$ and found to be satisfactory. Among various metal salts tested for proposed formylation reaction only $\mathrm{Cu}(\mathrm{II}), \mathrm{Ni}(\mathrm{II}), \mathrm{Co}(\mathrm{II})$,
$\mathrm{Zn}$ (II), and $\mathrm{Cd}(\mathrm{II})$ nitrates were found to be fairly soluble in $\mathrm{CH}_{3} \mathrm{CN}$ and more effective for promoting the reaction, whereas other salts are not soluble in ACN and the reaction is sluggish. Furthermore, to optimize the reaction conditions, the reactions are carried out by using different concentrations of metal salt ranging from one millimolar $(0.001 \mathrm{M})$ to centimolar solutions. Reactions underwent smoothly with very good regioselectivity (i.e., ortho-formylation) in $0.01 \mathrm{M}$ metal nitrate solutions in acetonitrile medium which could be seen from the data presented in Table 1 . The results 
TABLE 1: Metal-ion mediated formylation of phenol with Vilsmeier-Haack reagent.

(a)

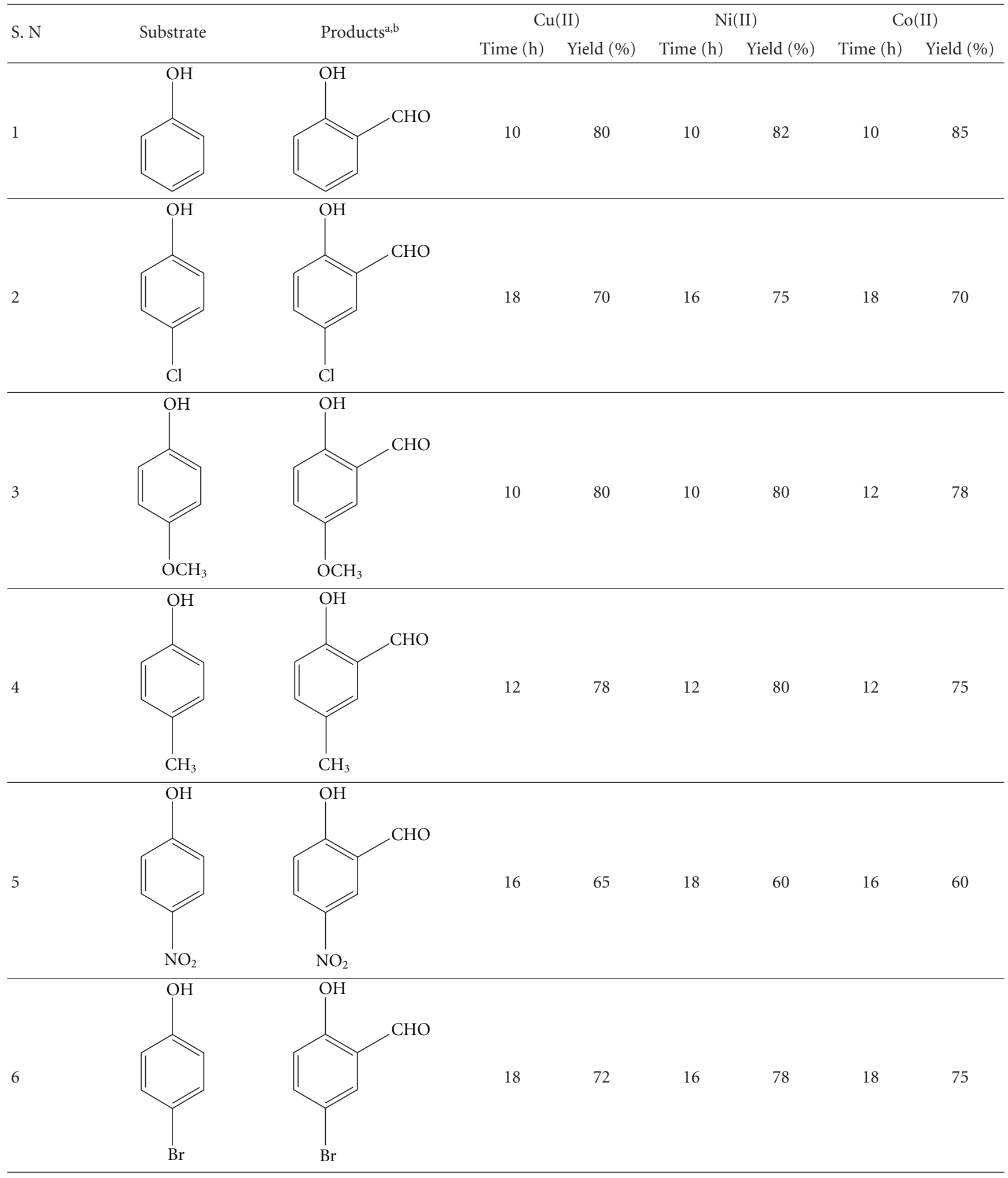


(a) Continued.

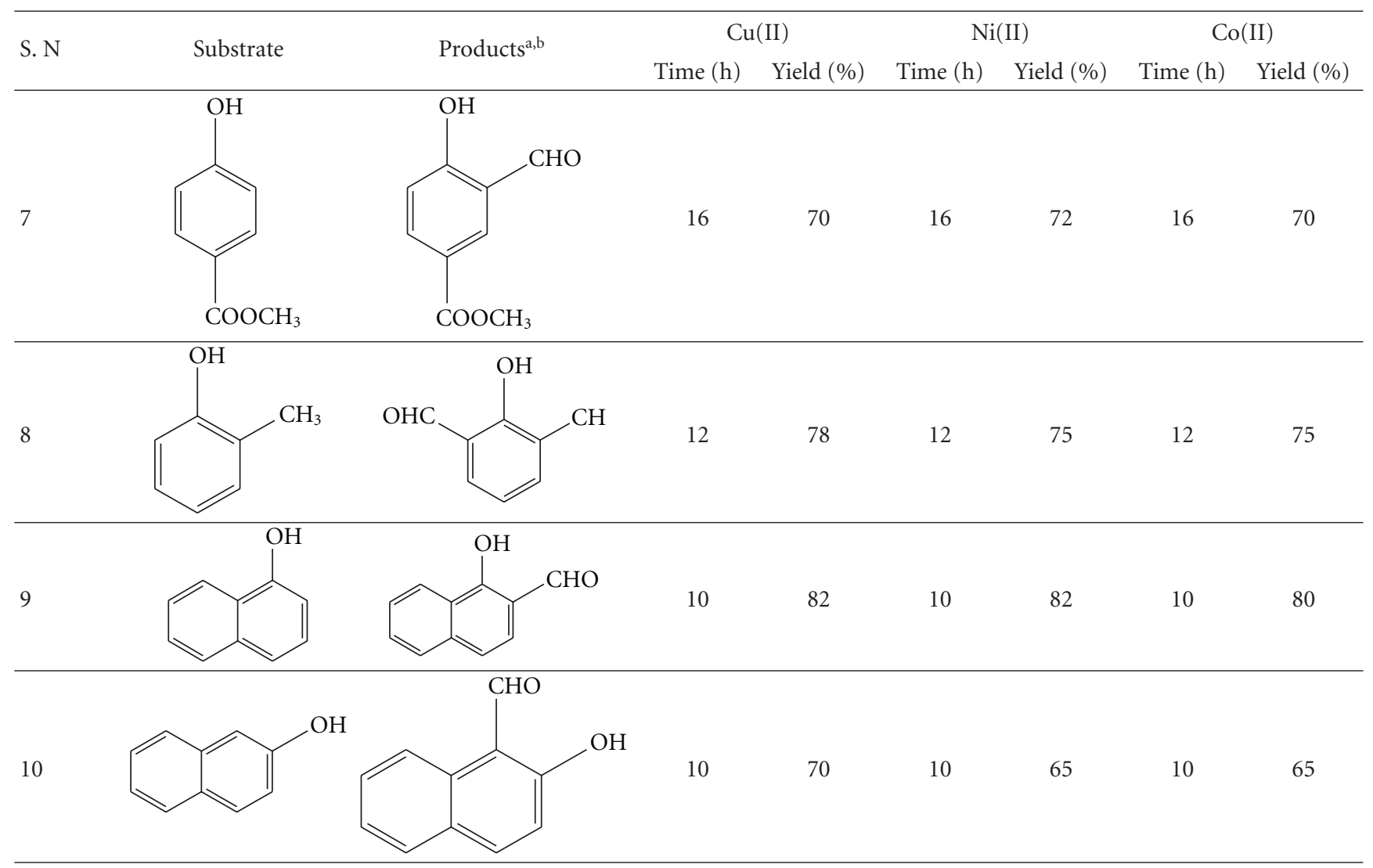

${ }^{a}$ All the products were characterized by usual spectral and analytical methods.

${ }^{\mathrm{b}}$ Isolated yields.

(b)

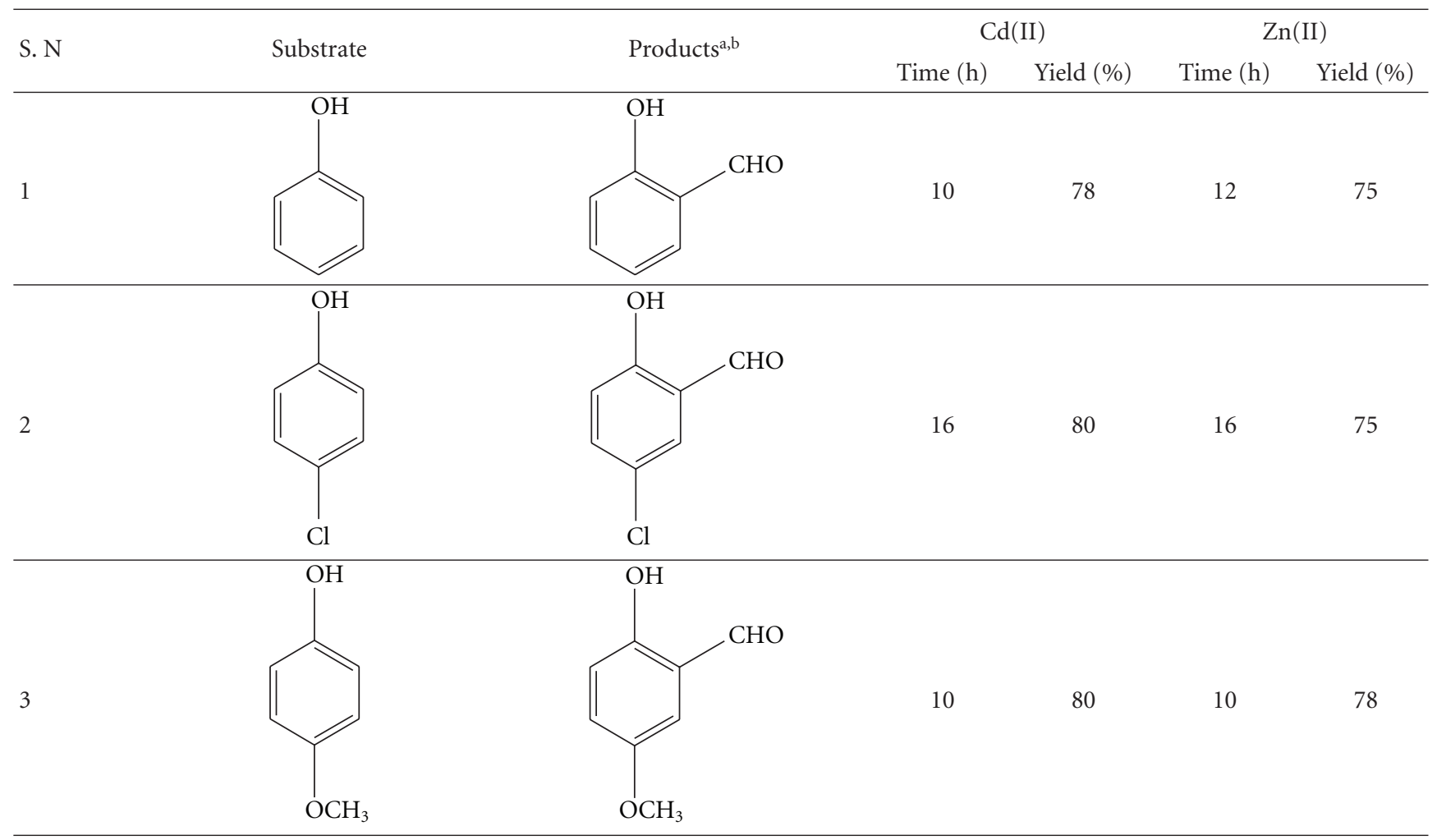


(b) Continued.

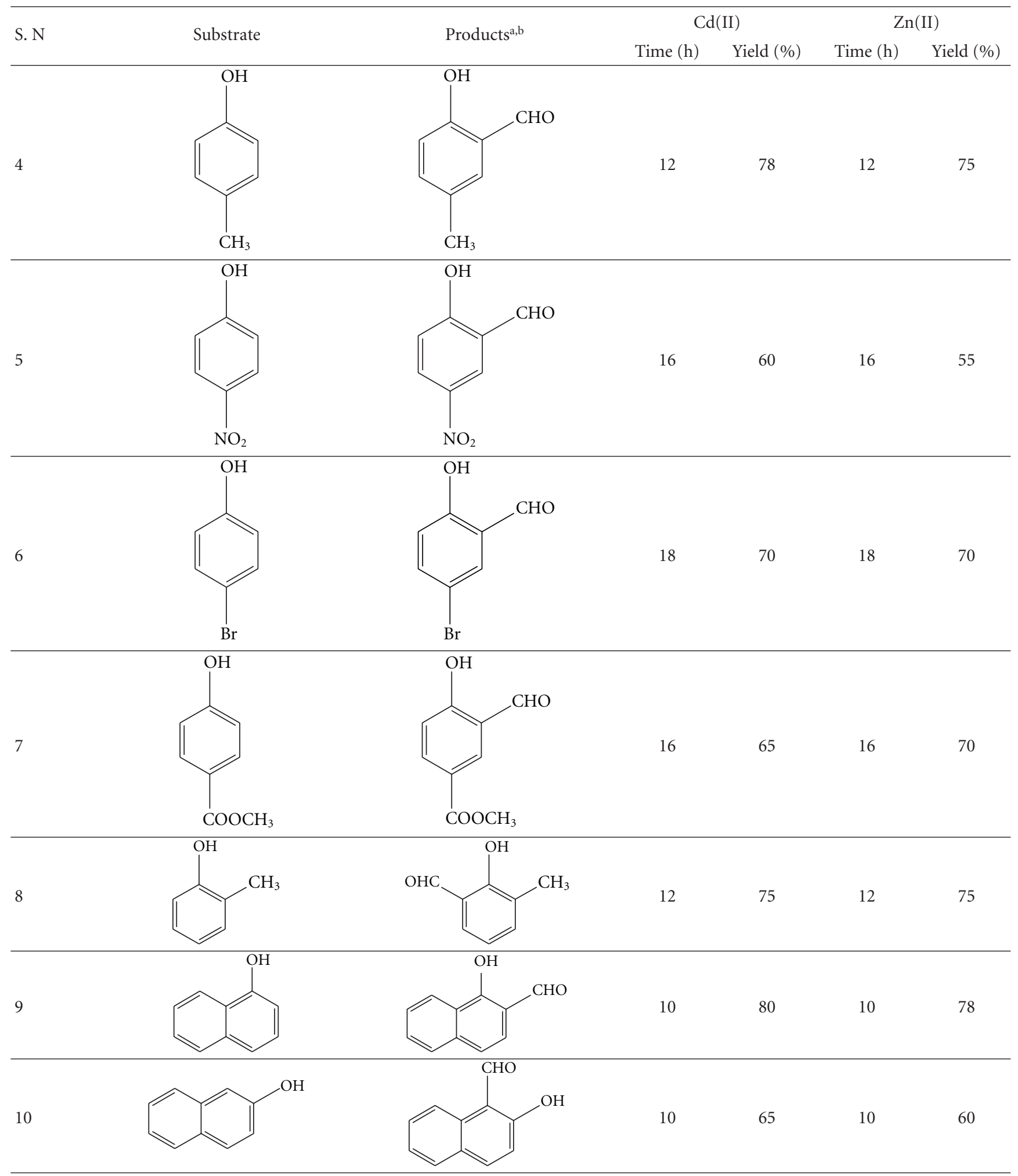

${ }^{a}$ All the products were characterized by usual spectral and analytical methods.

${ }^{\mathrm{b}}$ Isolated yields. 
clearly indicate that the ortho-formylation of phenols can be successfully achieved by employing $0.01 \mathrm{M}$ transition metal ion solution under $\mathrm{V}-\mathrm{H}$ condition which is not possible in classical condition. When the present formylation reaction is carried out in the absence of the metal ion the reaction was found to be too sluggish, even after $48 \mathrm{hrs}$ of reaction only 30\% conversion is observed. This observation supports efficient catalytic activity of transition metal nitrates used in this study. It is presumed that the reaction is initiated by the formation of metal salt of phenols in the first step, which is assumed to be a stable species and actively involved to direct the incoming electrophile via the reaction with iminium salt ( $\mathrm{V}-\mathrm{H}$ reagent) to attack at ortho position and finally to give formyl derivative on basic hydrolysis. The plausible reaction path is depicted in Scheme 2.

\section{Experimental Procedure}

Metal salt $(0.05 \mathrm{~mol})$ was added to a decimolar $(0.1 \mathrm{~mol})$ solution of substrate (phenol) in acetonitrile and stirred for 10 minutes. To this solution Vilsmeier-Haack adduct prepared from $9.3 \mathrm{~mL}(100 \mathrm{mmol}) \mathrm{POCl}_{3}$ in $9.29 \mathrm{~mL}$ ( $100 \mathrm{mmol}) \mathrm{DMF}$ at $-5^{\circ} \mathrm{C}$ was added. The reaction mixture was refluxed. The progress of the reaction was monitored by TLC after completion of the reaction. The reaction mixture was poured into crushed ice and treated with $5 \% \mathrm{NaHCO}_{3}$ solution. This was extracted with dichloromethane. The organic layer was separated and dried over sodium sulphate. The organic layer was evaporated to get the crude product which was purified by column chromatography using silica gel (60-120 mesh) and eluted with ethyl acetate, hexane $(20: 80)$ as eluent.

\section{Acknowledgments}

The authors are thankful to the principal and management of Muffakham Jah College of Engineering and Technology; Professor T. Navaneeth Rao (Former Vice Chancellor, O.U) and Professor P. K. Saiprakash (Former Dean, Faculty of Science, O.U) for constant encouragement and support to carry out the research work.

\section{References}

[1] J. P. Young and C. H. Jun, "Transition metal-catalyzed orthofunctionalization in organic synthesis," Bulletin of the Korean Chemical Society, vol. 26, no. 6, pp. 871-877, 2005.

[2] C.-H. Jun and J. H. Lee, "Application of C-H and C-C bond activation in organic synthesis," Pure and Applied Chemistry, vol. 76, no. 3, pp. 577-587, 2004.

[3] G. A. Olah, L. Ohannesian, and M. Arvanaghi, "Formylating agents," Chemical Reviews, vol. 87, no. 4, pp. 671-686, 1987.

[4] G. Solladié, A. Girardin, and G. Lang, "Synthesis of new aromatic retinoid analogues by low-valent titanium induced reductive elimination," Journal of Organic Chemistry, vol. 54, no. 11 , pp. 2620-2628, 1989.

[5] J. F. Larrow, E. N. Jacobsen, Y. Gao, Y. Hong, X. Nie, and C. M. Zepp, "A practical method for the large-scale preparation of $\left[\mathrm{N}, \mathrm{N}^{\prime}\right.$-Bis(3,5-di-tert-butylsalicylidene)-1,2cyclohexanediaminato(2-)] manganese(III) chloride, a highly enantioselective epoxidation catalyst," Journal of Organic Chemistry, vol. 59, no. 7, pp. 1939-1942, 1994.

[6] T. Laird, "Benzoin condensation," in Comprehensive Organic Chemistry, J. F. Stoddart, Ed., vol. 1, pp. 1105-1160, Perganon Press, Oxford, UK, 1979.

[7] C. M. Marson, "Reactions of carbonyl compounds with (monohalo) methyleniminium salts (Vilsmeier reagents)," Tetrahedron, vol. 48, no. 18, pp. 3659-3726, 1992.

[8] C. Jutz, "Iminium salts in organic chemistry [part I]," in Advances in Organic Chemistry, E. C. Taylor, Ed., vol. 9, p. 225, John Wiley \& Sons, New York, NY, USA, 1976.

[9] O. Meth-Cohn and B. Tarnowski, "Cyclizations under Vilsmeier Conditions," Advances in Heterocyclic Chemistry, vol. 31, pp. 207-236, 1982.

[10] O. Meth-Cohn and D. L. Taylor, "Vilsmeier formylation of para-substituted tert-anilines results in dibenzo[1,5]diazocines or quinazolinium salts: a remarkable example of the 't-amino effect', Journal of the Chemical Society, Chemical Communications, no. 14, pp. 1463-1464, 1995.

[11] A. Jackson and O. Meth-Cohn, "A new short and efficient strategy for the synthesis of quinolone antibiotics," Journal of the Chemical Society, Chemical Communications, no. 13, p. 1319, 1995.

[12] B. Balasundaram, M. Venugopal, and P. T. Perumal, "Synthetic studies on $\mathrm{N}$-acetyl derivatives of amino acids and thiolactone using Vilsmeier-Haack reagent," Tetrahedron Letters, vol. 34, no. 26, pp. 4249-4252, 1993.

[13] M. Venugopal and P. T. Perumal, "A new method for the synthesis of chloroindenes by Vilsmeier reagent," Synthetic Communications, vol. 21, no. 4, pp. 515-519, 1991.

[14] M. Venugopal, R. Umarani, P. T. Perumal, and S. Rajadurai, "A new method for the preparation of substituted 5,6,7,8tetrahydro $4 \mathrm{H}$-1-benzopyran and $4 \mathrm{H}$-pyrans by VilsmeierHaack reagent," Tetrahedron Letters, vol. 32, no. 27, pp. 32353238, 1991.

[15] V. J. Majo and P. T. Perumal, "The vilsmeier cyclization of azides. Synthesis of oxazoles and vinyl azides from 2azidoacetophenones," Tetrahedron Letters, vol. 38, no. 39, pp. 6889-6892, 1997.

[16] R. R. Amaresh and P. T. Perumal, "A novel one pot synthesis of 2-dimethylaminoquinoline derivatives from arylazido ketones by cyclization under Vilsmeier condition," Tetrahedron Letters, vol. 39, no. 22, pp. 3837-3840, 1998.

[17] V. J. Majo and P. T. Perumal, "Intramolecular cyclization of azides by iminium species. A novel method for the construction of nitrogen heterocycles under vilsmeier conditions," Journal of Organic Chemistry, vol. 63, no. 21, pp. 7136-7142, 1998.

[18] R. C. Boruah, S. Ahmed, U. Sharma, and J. S. Sandhu, "Synthesis of $\beta$-formylsteroidal enamides and their conversion into geminal dichlorides," Indian Journal of Chemistry B, vol. 38, no. 3, pp. 274-282, 1999.

[19] G. Kalisher, H. Scheyer, Keller et al., "Cyclic aldehydes," German Patent, 514415. Chem Abstract, vol. 25, pp. 1536, 1931.

[20] S. Morimura, H. Horiuchi, and K. Murayama, "Vilsmeier reaction of phenols I. Synthesis of aryl formates," Bulletin of Chemical Society of Japan, vol. 50, no. 8, pp. 2189-2190, 1977.

[21] K. C. Rajanna, M. Moazzam Ali, S. Sana, Tasneem, and P. K. Saiprakash, "Vilsmeier Haack acetylation in micellar media: an efficient one pot synthesis of 2-chloro-3-acetyl Quinolines," Journal of Dispersion Science and Technology, vol. 25, no. 1, pp. 17-21, 2004. 
[22] M. M. Ali, S. Sana, Tasneem, K. C. Rajanna, and P. K. Saiprakash, "Ultrasonically accelerated vilsmeier haack cyclisation and formylation reactions," Synthetic Communications, vol. 32, no. 9, pp. 1351-1356, 2002.

[23] S. Ramgopal, K. Ramesh, A. Chakradhar, N. M. Reddy, and K. C. Rajanna, "Metal nitrate driven nitro Hunsdiecker reaction with $\alpha, \beta$-unsaturated carboxylic acids under solventfree conditions," Tetrahedron Letters, vol. 48, no. 23, pp. 40434045, 2007.

[24] A. Chakradhar, R. Roopa, K. C. Rajanna, and P. K. Saiprakash, "Vilsmeier-haack bromination of aromatic compounds with $\mathrm{KBr}$ and N-bromosuccinimide under solvent-free conditions," Synthetic Communications, vol. 39, no. 10, pp. 1817-1824, 2009.

[25] G. Venkateshwarlu, A. Premalatha, K. C. Rajanna, and P. K. Saiprakash, "Cadmium chloride as an efficient catalyst for neat synthesis of 5-substituted $1 H$-tetrazoles," Synthetic Communications, vol. 39, no. 24, pp. 4479-4485, 2009.

[26] G. Venkateshwarlu, K. C. Rajanna, and P. K. Saiprakash, "Antimony trioxide as an efficient Lewis acid catalyst for the synthesis of 5-substituted 1H-tetrazoles," Synthetic Communications, vol. 39, no. 3, pp. 426-432, 2009.

[27] Tasneem, M. M. Ali, K. C. Rajanna, and P. K. Saiparakash, "Ammonium nickel sulphate mediated nitration of aromatic compounds with nitric acid," Synthetic Communications, vol. 31, no. 7, pp. 1123-1127, 2001.

[28] V. Kotlyar, L. Shahar, and J.-P. Lellouche, "A simple homemade reaction station for use in parallel solution-phase synthesis. Optimization of a regioselective one-step deprotective oformylation reaction mediated by the Vilsmeier-Haack reagent $\mathrm{POCl}_{3} \cdot \mathrm{DMF}$, Molecular Diversity, vol. 10, no. 2, pp. 255-264, 2006. 


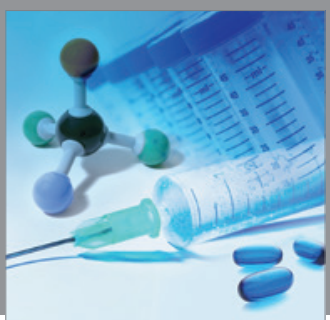

International Journal of

Medicinal Chemistry

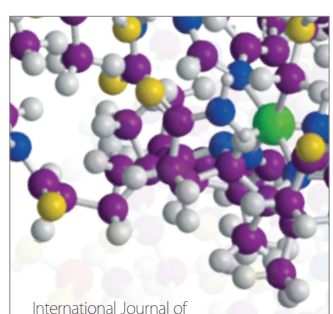

Carbohydrate Chemistry

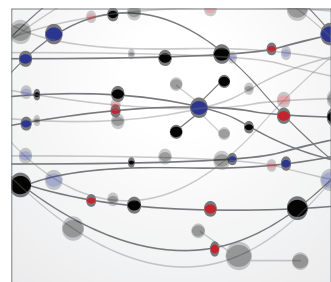

The Scientific World Journal
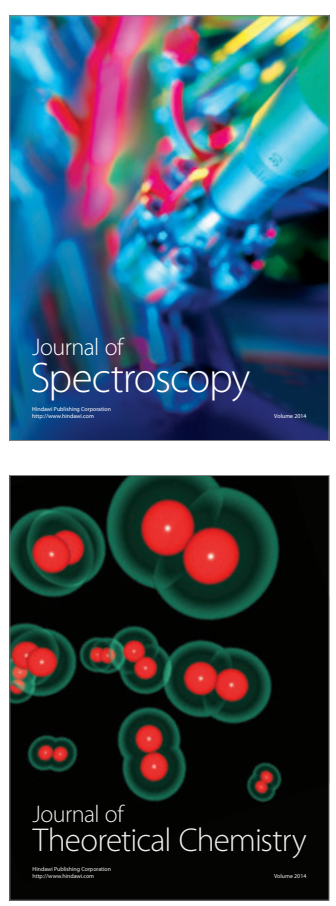
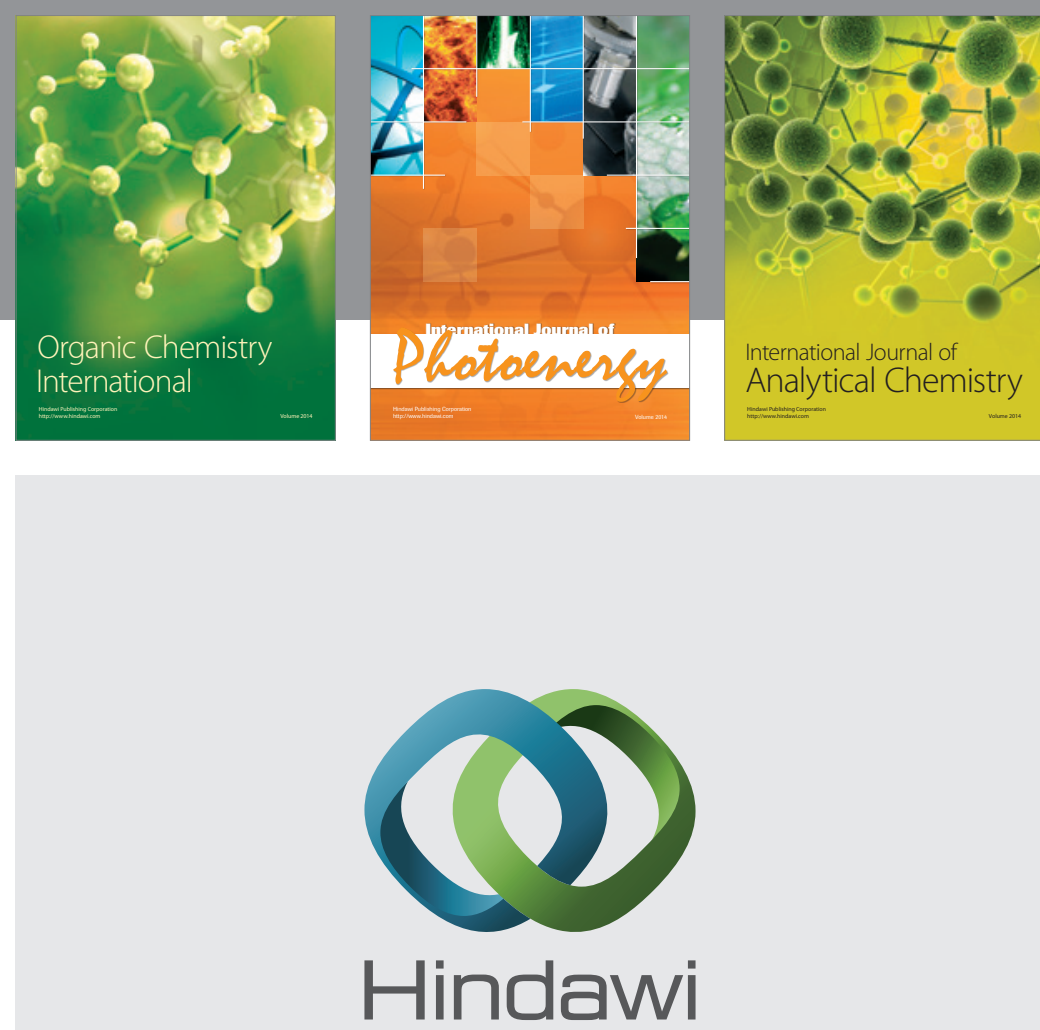

Submit your manuscripts at

http://www.hindawi.com
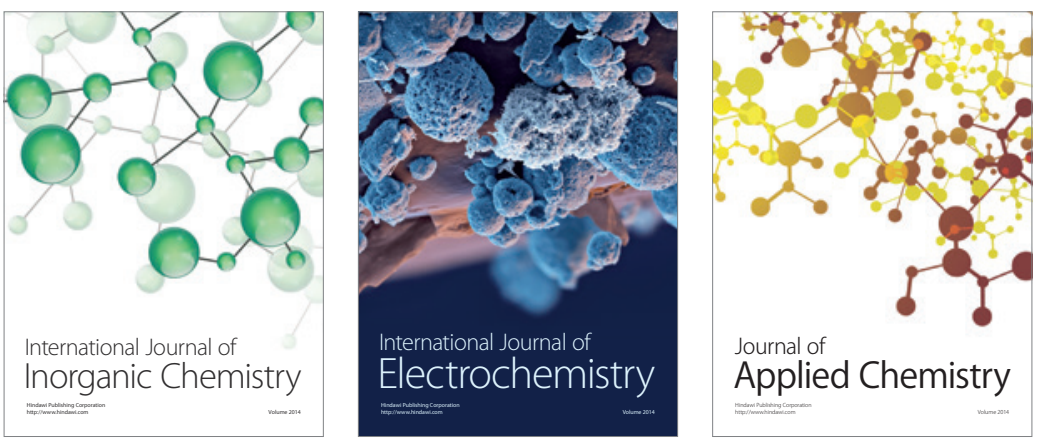

Journal of

Applied Chemistry
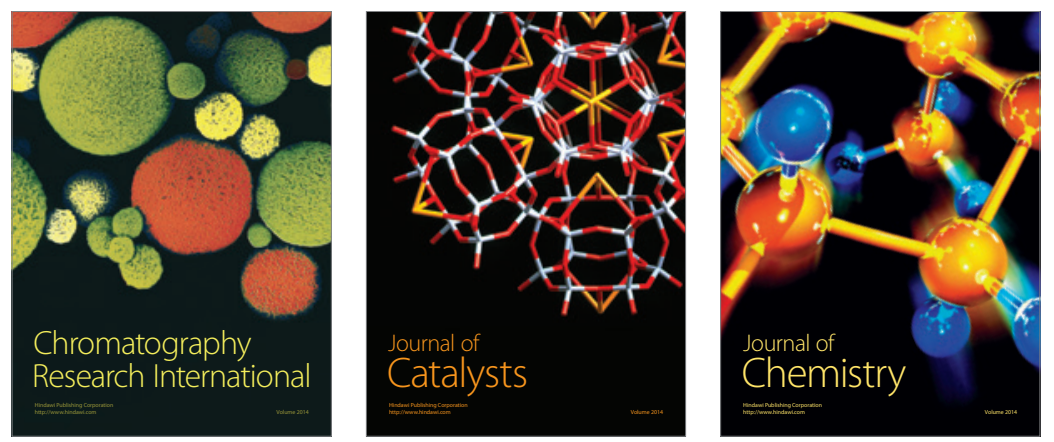
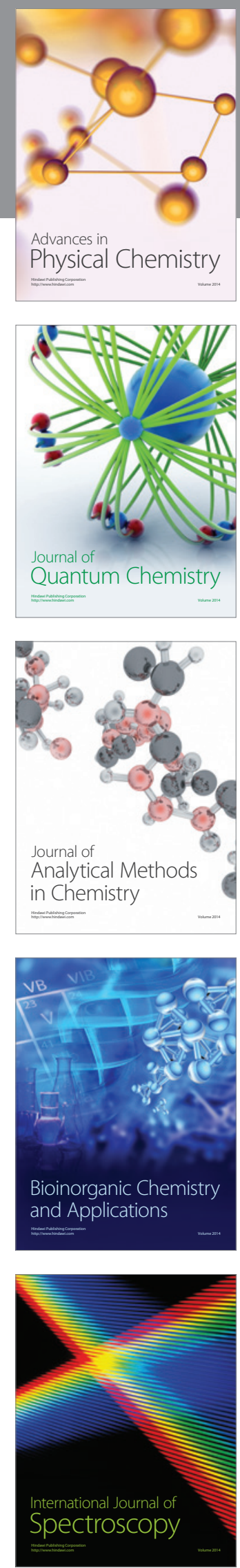